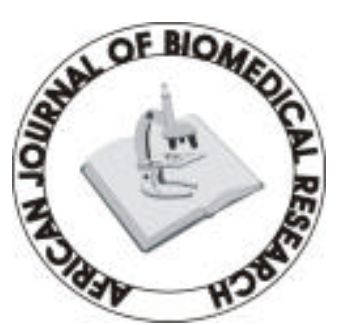

Full-text available at http://www.ajbrui.com $\&$

http://www.bioline.br/md

Received:

November, 2005

Accepted (Revised):

March, 2006

Published

May, 2006
Full length Research Article

\section{Age-specific association between percent body fat and pulmonary function in apparently normal children in Ogbomoso, Oyo State, Nigeria}

\author{
${ }^{1}$ Olabinri B.M; ${ }^{2}$ Olaleye MT; ${ }^{3}$ Akinola FF and ${ }^{4}$ Omotoso E.O \\ Departments of ${ }^{1}$ Biochemistry, ${ }^{3}$ Physiology and ${ }^{4}$ Anatomy Ladoke Akintola \\ University of Technology, Ogbomoso, Nigeria. \\ Department of ${ }^{2}$ Biochemistry, Federal University of Technology, Akure, Nigeria.
}

\section{ABSTRACT}

This study describes the association between percent body fat and pulmonary function among apparently normal twenty male children tidal volume aged 4 years and twenty male children aged 10 years in Ogbomoso. The mean functional residual capacity of the lung in male children aged 10 years was significantly higher than in male children aged 4 years $(\mathrm{P}<0.05)$. The mean tidal volume-functional residual capacity ratio were $0.32 \pm 0.04(\mathrm{SD})$ and 0.23 \pm 0.02 (SD) in male children aged 4 years and 10 years, respectively. There was no significant difference between the mean tidal volume - functional residual capacity ratio in both age groups $(\mathrm{P}>0.05)$. The mean percent body fat were $11.74 \%$ and $6.76 \%$ in male children age 4 years and 10 years, respectively. The mean percent body fat was significantly higher in male children aged 4 years than male children aged 10 years $(\mathrm{P}<0.001)$. There was a weak nonsignificant positive correlation between the functional residual capacity of the lung and percent body fat $(\mathrm{r}=0.30 ; \mathrm{P}=0.05)$ in male children aged 10 years while a high significant positive correlation was observed between the functional residual capacity of the lung and percent body fat $(\mathrm{r}=-0.68 ; \mathrm{P}=0.05)$ in male aged 4 years. The fact that the correlation between percent body fat and tidal volume-functional residual capacity ratio was high and significant $(\mathrm{r}=$ $0.76 ; \mathrm{P}=0.001$ ) suggests that the ratio might serve as an excellent marker to differentiate the nutritional state in both age groups in non-disease states ( $\boldsymbol{A} f \mathbf{f r} . \mathbf{J}$.

Biomed. Res. 9:83 - 87, May 2006)

Keywords : percent body fat; pulmonary function; modelling equation; tidal volume and functional residual capacity ratio

${ }^{1}$ Address for Correspondence: Olabinring@yahoo.com 


\section{INTRODUCTION}

Reduced pulmonary function is an important predictor of mortality in the general population (Friedman et al 1976; Schunemann et al 2000). Analysis for the values of lung subdivisions including total lung capacity (TLC), residual volume (RV) and functional residual capacity (FRC) demonstrated that standing and sitting height were the best predictors of lung volumes (Mary et al 2000).

Normal lung growth and development during intrauterine period and childhood are important for reaching maximum attainable adult lung function (Stratchan, 1997). It is well recognized that the sex and ethnically appropriate reference values are essential for interpreting lung function tests both clinically and in research studies (Stocks and Quanjer, 1995). Availability of appropriate reference value is essential for meaningful interpretation of the results of any pulmonary function tests (Stocks and Quanjer, 1995).

Lung volumes are also considerably influenced by the amount of body fat: gross: obesity decreases the total and chest wall compliance (Sharp et al 1964) and thus diminishes expiratory reserve volume and functional residual capacity (Emirgil and Sobol, 1973; Ray et al 1983).

There are as yet no prediction equations which span the whole age range from childhood to old age (Ghio et al 1990; Patishall, 1990; Sitarama et al 2004). The majority of prediction equations have been calculated by the traditional linear regression equation method, a model first described by Hutchinson in 1846 which remains popular primarily on account of its simplicity. There is a clear evidence for the influence of sex, ethnic origins and age/development stage as determinant of lung volume in school age children and adults (Rahman et al 1990; Quanjer et al 1993) which should not be ignored.

The most important applications of anthropornetry at field level include biological anthropology, epidemiology, clinical applications and metabolic research (Solomon et al 1993). Measuring skin fold thickness at four sites ( triceps, subscapular and iliac crest) that quantify subcutaneous adipose tissue thickness on the limbs and trunk can make an accurate assessment of body fat (During and Wormersley 1974; Oe et al 1998; Kopple et al 1999). The best estimators of body density in children and adolescents were log sigma four skin folds and combinations of BMI and tricep skin fold (Sarria et al 1998).

To date, the association between percent body fat and pulmonary function has not been reported among apparently normal male children residential Ogbomoso, Nigeria. This study aims to identify a possible pulmonary marker, which when used in conjunction with percent body fat could help differentiate the nutritional state of male children aged 4 years from male children aged 10 years in Ogbomoso in view of perceived decrease in percent boy fat in Nigerian children as age increases.

\section{MATERIALS AND METHOD}

\section{Study population}

Participants used in this study were twenty male school children aged 4 years and twenty male school children aged 10 years who are attending a public primary school in Ogbomoso, Nigeria. Ogbomoso is the second largest in Oyo State, Nigeria. The children were enrolled into study after from permission from the Head master and their teachers. All the children are Yoruba children resident in Ogbomoso, Nigeria

\section{Anthropometric measure}

The height of each child was measured using a ruler with each child standing feet without shoes, back and heel against a vertical ruled bar according to a standard procedure (Whitney et al 1998). The weight of each child was measured in light clothing without shoes (Watts et al 2003) using a bathroom scale. The tricep skinfold thickness was measured over the left tricep muscle at a level midway between the acromnion and oleoranon process with the arm hanging down at the side (Taylor et al 1996) using a vernier caliper(Holtain Ltd, UK). The subscapular skin fold thickness was measured just below the tip of the scapula (Lohman, 1984). The tricep and subscapular skinfold thickness of each child was convered to percent body fat using a modeling equation (Slaughter et al 1988).

\% Body fat $=1.21$ (tricep + subscapular skinfold $)-0.008$

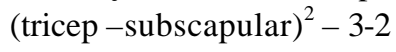

The functional residual capacity of the lung of each child was estimated by a functional residual capacity modeling equation (Parker et al 2003).

\section{For males less than 1.626 metres}

$\mathrm{FRC}=[0.02394 \mathrm{x}$ stand height $(\mathrm{cm})]+(-1.716)$

where FRC is the functional residual capacity of the lung.

\section{For males greater than 1.626 metres}

The tidal volume for the lung of each child was assessed using a tidal volume modelling equation reported by the same investigator (Parker et al 2003).

$\log \mathrm{TV}=[1.8643 \times \log$ stand height $(\mathrm{cm})]-1.3956$

$\mathrm{TV}=\log ^{-1} \mathrm{x}$

where $\mathrm{TV}=$ tidal volume.

\section{Statistical analysis}

Student's t-test was used for statistical analysis. P-values less than 0.05 or 0.001 were considered significant. 


\section{RESULTS AND DISCUSSION}

Skin fold thicknesses are commonly measured in clinical and field settings for the assessment of percent body fat because the method is simple to perform and low in cost (Heymsfield et al 1990). Two of the most widely used skinfold thickness equations are those developed by Durnin and Wormersley, and Jackson and Pollock(Durmin and Wormersley, 1974; Jackson and Pollock 1978).

Previous studies have explored the predictive accuracy and precision of the Jackson and Pollock, and Durnin and Wormersley equations in different populations (Carey, 2000; Piers et al 2000; Lanham et al 2001). Only two equations were developed specifically for children and adolescents (Brook, 1971; Slaughter et al 1988).

The present study, the first of its kind on the subject, demonstrates unequivocally for the first time, that percent body fat correlates highly and significantly with a pulmonary parameter (tidal volume-functional residual capacity ratio) $(\mathrm{r}=0.76 ; \mathrm{P}=0.001)$ in male children aged 4 years in Ogbomoso. The fact the correlation was high suggests that tidal volume-functional residual capacity ratio when used in conjunction with percent body fat might serve as an excellent marker to differentiate the nutritional state in both age groups in non-disease states.

The mean tidal volume-functional residual capacity ratio (TV/FRC) was $0.32 \pm 0.04$ (SD) in male children aged 4 years while that of male children aged 10 yeas was $0.23 \pm$ 0.02 (SD) (table 1). There was no significant difference in the mean tidal volume-functional residual capacity ratio in both age groups $(\mathrm{P}>0.05)$. The present study also demonstrates unequivocally, for the first time, that a weak positive association $(\mathrm{r}=0.30 ; \mathrm{P}=0.05)$ which was not significant existed between percent body fat and functional residual capacity in male children aged 10 years while a high negative correlation was observed between percent body fat and functional residual capacity in male children aged 4 yeas resident in Ogbomoso who are of Yoruba origin $(\mathrm{r}=-0.68 ; \mathrm{P}=0.05)$ (table 2$)$.

The tidal volume in male children aged 10 years ranged from 307.61 to $380.54 \mathrm{ml}$ while the tidal volume in male children aged 4 years ranged from 168.66 to $218.07 \mathrm{ml}$ as shown in table 1 . The functional residual capacity ranged from 1284.00 to $1716.00 \mathrm{ml}$ in male children aged 10 years, and from 468.00 to $852.00 \mathrm{ml}$ in male children aged 4 years. (Table 1).

Table 1:

The physical, pulmonary and nutritional parameters of male children respondents aged 4 and 10 years

\begin{tabular}{|c|c|c|}
\hline & Male ( 10 year) $n=20$ & Male (4 year), $n=20$ \\
\hline mean age \pm SD (years) & $10.00 \pm 0.00$ & $4.00 \pm 0.00$ \\
\hline mean weight \pm SD kg) & $27.16 \pm 3.97$ & 14. $89 \pm 1.09$ \\
\hline mean height $\pm \mathrm{SD}(\mathrm{m})$ & $1.34 \pm 0.05$ & $0.99 \pm 1.09$ \\
\hline mean $\mathrm{BMI} \pm \mathrm{SD}\left(\mathrm{kg} / \mathrm{m}^{2}\right)$ & $15.42 \pm 1.62$ & $14.89 \pm 1.09$ \\
\hline mean tricep skinfold thickness $\pm \mathrm{SD}(\mathrm{mm})$ & $5.24 \pm 1.49$ & $5.84 \pm 1.99$ \\
\hline mean subscapular skin fold thickness $\pm \mathrm{SD}(\mathrm{mm})$ & $4.71 \pm 1.03$ & $7.53 \pm 2.32$ \\
\hline percent body fat $\pm \mathrm{SD}(\%)$ & $6.76 \pm 2.01$ & $11.74 \pm 4.58$ \\
\hline range of body fat & $3.83 \pm 9.80$ & $6.45-23.42$ \\
\hline mean tidal volume $\pm \mathrm{SD}(\mathrm{ml})$ & $353.03 \pm 24.08$ & $208.46 \pm 20.58$ \\
\hline range of tidal volume $\pm \mathrm{SD}(\mathrm{ml})$ & $307.61-380.54$ & $168.66-218.07$ \\
\hline mean FRC $\pm \mathrm{SD}(\mathrm{ml})$ & $1489.90 \pm 122.20$ & $661.26 \pm 129.36$ \\
\hline range of $\mathrm{FRC} \pm \mathrm{SD}(\mathrm{ml})$ & $1284.00-1716.00$ & $468.00-852.00$ \\
\hline $\mathrm{TV} / \mathrm{FRC} \pm \mathrm{SD}$ & $0.23 \pm 0.20$ & $0.32 \pm 0.04$ \\
\hline range of TV/ FRC & $0.18-0.25$ & $0.28-0.44$ \\
\hline $\mathrm{FRC} / \mathrm{TV} \pm \mathrm{SD}$ & $4.00-5.58$ & $2.49-3.59$ \\
\hline mean of FRC/TV & $4.23 \pm 0.34$ & $3.16 \pm 0.37$ \\
\hline
\end{tabular}

TV indicates tidal volume; FRC indicates functional residual capacity; TV/FRC indicates tidal volume -functional residual capacity ratio; FRC/TV indicates functional residual capacity - tidal volume ratio and BMI indicates body mass index. 


\section{Table 2:}

Pearson's correlations between percent body fat and pulmonary parameters in apparently normal male children respondents aged 10 and 4 years in Og bomoso.

\begin{tabular}{|c|c|c|}
\hline 2 & $\begin{array}{l}\text { Male (10 years) } \\
\% \text { Body fat }\end{array}$ & $\begin{array}{l}\text { Male (4 years) } \\
\% \text { Body fat }\end{array}$ \\
\hline Tidal volume & $\begin{array}{l}\mathrm{r}=-0.02 \\
\mathrm{P}=0.05 \\
\text { NS }\end{array}$ & $\begin{array}{l}r=-0.43 \\
P=0.05 \\
N S\end{array}$ \\
\hline Functional residual capacity & $\begin{array}{l}r=-0.30 \\
P=0.05 \\
\text { NS }\end{array}$ & $\begin{array}{l}r=-0.68 \\
P=0.05 \\
S G\end{array}$ \\
\hline TV/FRC & $\begin{array}{l}r=-0.32 \\
P=0.05 \\
N S\end{array}$ & $\begin{array}{l}\mathrm{r}=-0.76 \\
\mathrm{P}=0.001 \\
\mathrm{SG}\end{array}$ \\
\hline FRC/TV & $\begin{array}{l}r=-0.31 \\
P=0.05 \\
\text { NS }\end{array}$ & $\begin{array}{l}r=-0.77 \\
P=0.05 \\
S G\end{array}$ \\
\hline
\end{tabular}

$T V=$ tidal volume; $F R C=$ functional residual capacity; NS indicates not significant; SG indicates significance.

The TV/FRC ratio ranged from 0.18 to 0.25 in male children aged 10 years and from 2.49 to 3.59 in male children aged 4 years.

The percent body fat ranged from 6.45 to $23.42 \%$ in male children aged 4 years and from 3.8 to $9.8 \%$ in male children aged 10 years. The mean percent body fat were $11.74 \%$ and $6.76 \%$ in male children aged 4 years and 10 years, respectively. The mean percent body fat was higher in male children aged 4 years than female children aged 10 ,ands the difference was significant $(\mathrm{P}<0.001)$. This indicates that male children aged 4 years had a better nutrition than male children aged 10 years .

The values predicted in the present study for the mean percent body fat for male children aged 4 yearts and male children aged 10 years resident in Ogbomoso,Nigeria were obtained using a modelling equation of Slaugher et al (1988). The value of present body fat $(11.74 \%)$ was obtained for male children aged 4 years in the present study, a value similar to that of male children with the age range $(20-29$ years) reported elsewhere (Taylor et. al) for male Nigerians resident in Ibadan (the largest City in Oyo State ,Nigeria) who adopted a different modelling equation of Brozek(1991).

Skinfold anthropometry is a well established clinical method for measuring body fat (Alpiers et al 1995). About one half of the body's fat content is found in the subcutaneous layer (Chumlea et al 1998). Measuring skinfold thickness at four sites (triceps, biceps, subscapular and iliac crest) that quantify subscapular adipose tissue thickness on the limbs and trunk can make an accurate assessment of body fat (Durnin and Wormersley, 1974; Oe et al 1998; Kopple et al 1999).
A single skinfold thickness may still be valuable provided standards appropriate to the ethnic groups are used (Prijatmoko and Strauss, 1995). The field setting, as district from clinical and laboratory settings, relates to the study of populations and sub populations (Solomons and Mazariegos, 1995).

In conclusion, a pulmonary parameter (tidal volume functional residual capacity ratio) when used in conjunction with percent body fat assists in the differential prediction of the nutritional state in nondisease states of male children aged 4 years and male children aged 10 years resident in Ogbomoso, Nigeria.

\section{REFERENCES}

Bach, P. H. (1997) The renal medulla and distal nephron toxicity, in Sipes IG, McQueen CA, Gandolfi A J. (eds): Comprehensive Toxicology, Vol. 7. Oxford, England; Elsevier, pp 279-298.

Bush, B. M. (1991). Interpretation of Laboratory results for small animal clinicians. Blackwell Scientific Publications London.

Elsevier, M. M., DeBroe, M. E. (1998) Analgesics, in DeBroe M. E. Porter, G. A. Bennett, A. M. Verpooten, G. A. (eds): Clinical Nephrotoxicants, Renal injury from Drugs and Chemicals. The Netherlands: Kluwer, pp189-202.

Cook, H. C. (1973) Histopathology: Selected Topics. Bailliere Tindall.

Crocker, C.L. (1967). Rapid determination of urea nitrogen in serum or plasma without deproteinization. Am. J. Med. Technol 334, 361-363.

Duncan, J. R., Prasse, K. W., Mahaffey, E. A. (1994) 
Veterinary Laboratory Medicine. Clinical Pathology. $3^{\text {rd }} \mathrm{Ed}$. Iowa State University Press, Ames, Iowa.

Gilman, A. G.; Goodman, L. S.and Gilman, A. (1990). The Pharmacological Basis of Therapeutics. $6^{\text {th }}$ Edition Macmillian Pub. Co. Inc. New York.

Gornall A. G., Bardawill C. J., David, M. M.(1949). Determination of serum proteins by means of the biuret reagent. J. Biol. Chem. 177, 751-755.

Gupta, R. A. and DuBois, R. N. (1999) Aspirin, NSAIDs, and colon cancer prevention. Mechanism? Gastroenterology, 114, 1095-1098.

Hodgson, E and Levi, R.E.(1985). Test book of modern Toxicology. Elsevier Science Publ. Co. Inc., New York.

Jain, N. C. (1986). Schalm's Veterinary Hematology. $4^{\text {th }}$ Lea and Febinger. Philadelphia.

Kaneko, J. T. Cornelius, C. E. (1985) Clinical Biochemistry of domestic animals. Academic Press. NY.

Klaassen, C. D. (2001) Casarett and Doull F Toxicology: the Basic Science of Poison. $6^{\text {th }}$ Eds The McGrau-Hill Companies Inc. New York.

Michealsson M.. (1961). Bilirubin determination in serum and urine. Scand. J. Clin. Lab. Invest. Suppl. 56, 1.

Osweiler, G. D., Carson, T. L, Buck, W. B. and Van
Gelder, G. A.. (1985) Clinical and Diagnostic Veterinary Toxicology. $3^{\text {rd }}$ Ed., Kendall/Hunt Publ. Com., Iowa

Sigma Diagnostic (1985). Quantitative, Colorimetric Determination in Serum, Plasma or Cerebrospinal Fluid. (Procedure No. 505)

Smith, Jones, and Hunt, (1986) Veterinary Pathology. Lea and Febiger

Steel, R. G. D. and Torie, J. H.(1986.) Principles and Procedure of statistics, A Biometric approach. McGraw Hill, New York.

Tarloff, J. B. (1997). Analgesics and Non steroidal antiinflammatory drugs, in Sipes I. G., McQueen C. A. Gandolfi, A. J. (eds): Comprehensive Toxicology. Vol. 7, Oxford, England: Elsevier, pp583-600.

Whelton, A. Watson, A. J. (1998) Non steroidal antiinflammatory drugs: effects on kidney interstitial nephritis, in DeBroe M. E., Porter G. A., Bennett, A. M., Verpooten G. A. (eds): Clinical Nephrotoxicants, Renal Injury from Drugs and Chemicals. The Netherlands: Kluwer, pp203-216 Young, N. S. (1997): The pathophysiology of acquired aplastic anemia. N. Engl J. Med 336,1365-1372.

Young, N. S.(1999) Acquired aplastic anemia. JAMA 282: 271-278 